\title{
New technique for the complicated canalicular injuries
}

\author{
Ahmet Ozer* and Afsun Sahin \\ Department of Ophthalmology, Medical Faculty, Eskişehir Osmangazi University, Eskişehir/Turkey
}

\begin{abstract}
In lacrimal system lacerations the canaliculi are involved in many of cases. Canalicular lacerations need urgent primary microsurgical repair. During surgery, it is extremely difficult to find the medial ostium of the canaliculi in severely damaged canaliculi cuts. In this instance, pigtail probe helps surgeon locate the medial portion of the cut canaliculi. In this study, a new technique has been presented for the complicated canalicular injuries. With this new technique the knot will stay in the nasal cavity unexposed, therefore the patients will be more comfortable during their recovery period.
\end{abstract}

\section{Introduction}

Silicon tube intubation during canalicular damage repair is a necessary procedure in order to obtain patent opening. It is an easy procedure in the case of smooth canalicular cuts. However, it is extremely difficult to locate the proximal end of the canalicular in complicated cuts [1-6]. In these situations, pigtail probe is very useful to find the medial end of the canaliculi and implantation of silicone tube. When medial segment is found and if it possible to reach to nasal cavity through this segment, monocanalicular tubes would be enough to complete intubation successfully. However, in severe damaged canalicular cuts, and in cases when it is impossible to reach canaliculi from medial segment, a silicone tube is attached to pigtail with prolen sutures and this pigtail probe is pulled through the secure canaliculi and withdrawn from the other punctum. Then, following repairment of cut, silicone tubes are tied in order to keep ties in the medial cantus. This tube is left about 3 to 6 months in order to complete recover of the canaliculi. However, the knot in the medial cantus poses ocular surface problems such as stinging and irritation of ocular surface.

From this point of view, a new technique is described which keeps silicone tube knot in the nasal cavity in order to prevent ocular surface damage.

\section{Method}

\section{Lower canaliculi cuts}

Upper punctum is dilated with a punctum dilatator. Pigtail probe is placed through the upper canaliculi and the medial portion of lower canaliculi is located. Silicon tube is inserted through lower punctum and is pulled through the lateral portion of the cut canaliculi. The probe of the silicone tube is removed and the tip of the tube is attached to pigtail probe with a $5 / 0$ prolen suture (Figure 1). Pigtail probe is pulled through carefully and silicone is caught from the upper punctum. Silicone tube is deattached by a scissor from the pigtail probe (Figure 2 ). On the second stage, a new probe is attached which allows an access to the nasal cavity, to free the end of the silicone tube. Following enough dilatation of the punctum, this new probe goes through the upper canaliculi and it is pulled through the nose with an aid of nasal speculum (Figure 3). In this situation, a silicone tube intubation with one end in the lower punctum and the other end in the nasal cavity is accomplished (Figure 4). If bicanalicular intubation is wanted, third stage is performed. In this instance, the probe mentioned above is attached to the free end of the silicone tube on the lower punctum. This probe goes through upper punctum and is pulled through nasal cavity as mentioned above (Figure 5). In this example, both tubes are intubated and pulled through the nose. The free ends of the tubes are tied in the nasal cavity (Figure 6).

\section{Upper canaliculi cuts}

Lower punctum is dilated enough with a punctum dilatator. Pigtail probe goes through the lower canaliculi and the medial portion of the upper canaliculi is located. Silicone tube goes through upper punctum and is pulled through lateral portion of the cut canaliculi. The probe of the silicone tube is removed and the tip of the tube is attached to

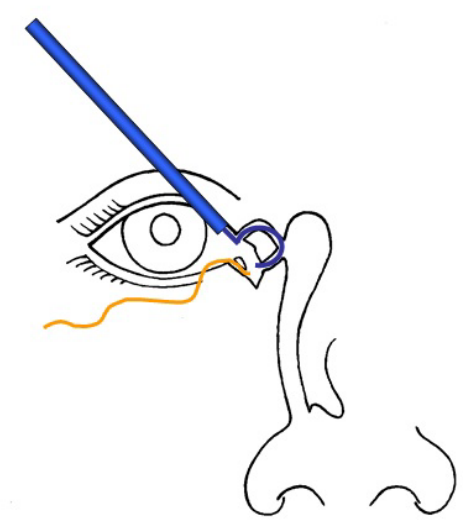

Figure 1. Pigtail prob goes through the upper canaliculi and the medial portion of lower canaliculi is located. Silicon tube goes through lower punctum and pulled through lateral portion of the cut canaliculi. The probe of the silicone tube is removed and the tip of the tube is attached to pigtail probe with a $5 / 0$ prolen suture.

Correspondence to: Prof. Dr. Ahmet Ozer, Eskisehir Osmangazi University Medical Faculty, Department of Ophthalmology, Eskisehir/ Turkey; Tel: 00902222291001; Fax: 00902222390928; E-mail: aozer@ogu.edu.tr

Key words: canalicular damage, pigtail probe, silicone intubation

Received: June 20, 2016; Accepted: July 14, 2016; Published: July 19, 2016 


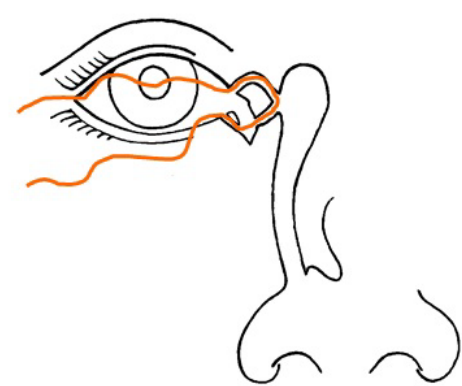

Figure 2. Pigtail probe is pulled through carefully and silicone is catched from the upper punctum. Silicone tube is deattached by a scissor from the pigtail probe.

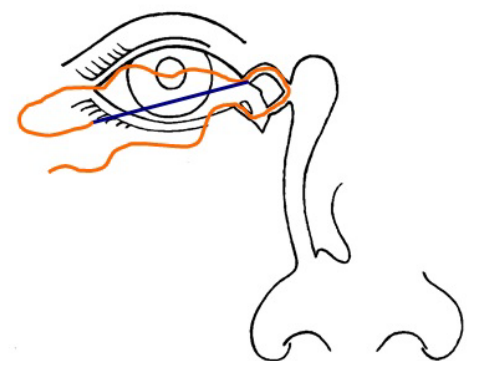

Figure 3. A new probe is attached which allows access to nasal cavity, to free end of the silicone tube. Following enough dilatation of the punctum, this new probe goes through the upper canaliculi and it is pulled through the nose with an aid of nasal speculum.

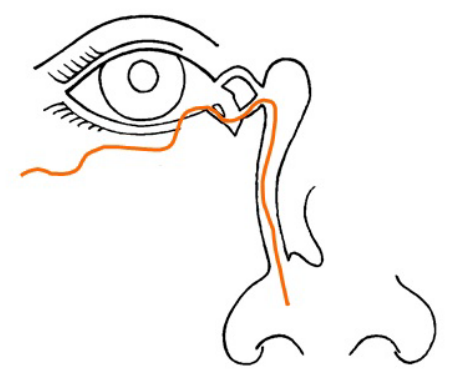

Figure 4. In this situation, a silicone tube intubation with one end in the lower punctum and the other end is in the nasal cavity is accomplished.

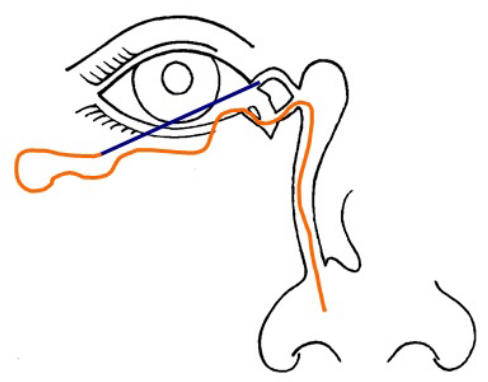

Figure 5. If bicanalicular intubation is wanted, third stage is performed. In this instance, the probe mentioned above is attached to the free end of the silicone tube on the lower punctum. This probe goes through upper punctum and pulled and pulled through nasal cavity.

pigtail probe with 5/0 prolen suture. Pigtail is pulled through carefully and silicone tube is caught from the lower punctum. Silicone tube is separated by a scissor from the pigtail probe. On the second stage a new probe is attached, which allows access to nasal cavity, to the free end of the silicone tube. Following enough dilatation of the punctum, this new probe goes through the lower canaliculi and is pulled through the nose with an aid of nasal speculum. In this situation, a silicone tube intubation with one end in the upper punctum and the other end is in the nasal cavity is accomplished.

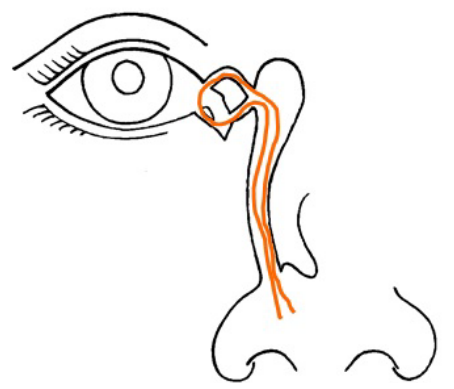

Figure 6. The free ends of the tubes are tied in the nasal cavity.

\section{Discussion}

In lacrimal system lacerations the canaliculi are involved in $70 \%$ of cases [7]. The inferior canaliculus is the most commonly affected but both canaliculi can be damaged by injuries [8]. Lacrimal system lacerations may occur the results of sharp or blunt trauma. Canalicular lacerations need urgent primary microsurgical repair with silicone intubation. During of procedure, it is extremely difficult to find the medial ostium of the canaliculi in severely damaged canaliculi cuts [16]. We herein presented a surgical approach of retrograde approach by using an endoscope to identify the medial ends of canalicular laceration [9]. In these instances, pigtail probe helps surgeon locate the medial portion of the cut canaliculi. However, in several damaged cases, silicone tube is pulled through the healthy punctum with the aid of the pigtail probe. The free ends of the silicone tube are tied in the medial cantus but this knot significantly irritates ocular surface. In this article, we presented a new technique for the complicated canalicular injuries. With this new technique the knot will stay unexposed in the nasal cavity and the patients will be symptom free during their recovery period.

\section{References}

1. Jordan DR, Gilberg S, Mawn LA (2008) The round-tipped, eyed pigtail probe for canalicular intubation: a review of 228 patients. Ophthal Plast Reconstr Surg 24: 176180. [Crossref]

2. Lee H, Chi M, Park M, Baek S (2009) Effectiveness of canalicular laceration repair using monocanalicular intubation with Monoka tubes. Acta Ophthalmol 87: 793-796. [Crossref]

3. Rosser PM, Burt B, Osborne SF (2010) Determination of the function of a repaired canaliculus after monocanalicular injury by placing a punctal plug in the non-involved punctum on the affected side. Clin Experiment Ophthalmol 38: 786-789. [Crossref]

4. Eo S, Park J, Cho S, Azari KK (2010) Microsurgical reconstruction for canalicular laceration using Monostent and Mini-Monoka. Ann Plast Surg 64: 421-427. [Crossref]

5. Wu SY, Ma L, Chen RJ, Tsai YJ, Chu YC (2010) Analysis of bicanalicular nasal intubation in the repair of canalicular lacerations. Jpn J Ophthalmol 54: 24-31. [Crossref]

6. Jordan DR, Mawn L (2008) Repair of canalicular lacerations. Am J Ophthalmol 146: $792-793$

7. Struck HG (2009) Lacrimal system lacerations and their surgical repair. Ophthalmologe 106: 223-228. [Crossref]

8. Ducasse A, Arndt C, Brugniart C, Larre I (2016) Lacrimal traumatology. J Fr Ophtalmol 39: 213-218. [Crossref]

9. Wu AY, Tucker NA (2011) Bicanalicular laceration repair via an endoscopic retrograde approach. Ophthal Plast Reconstr Surg 27: 165-167. [Crossref]

Copyright: (C2016 Ozer A. This is an open-access article distributed under the terms of the Creative Commons Attribution License, which permits unrestricted use, distribution, and reproduction in any medium, provided the original author and source are credited. 